This is the author's peer-reviewed, post-print manuscript as accepted for publication. The publisherformatted, penultimate version may be available through the journal web site or your institution's library.

\title{
An overview of family systems approaches to library management
}

Mark Stover

Manuscript Citation:

The following APA style citation may be used to reference this manuscript:

Stover, M. (2003). An overview of family systems approaches to library management. Retrieved from http://scholarworks.csun.edu

Version of Record Information:

Citation: Stover, M. (2003). An overview of family systems approaches to library management. Library Management, 24(8/9), 423-432.

Copyright: Copyright @ Emerald Publishing Group

(DOI): 10.1108/01435120310501103

URL: http://www.emeraldinsight.com/journals.htm?issn=0143-5124

Retrieved from CSUN ScholarWorks, the open-access, institutional repository of California State University, Northridge. http://scholarworks.csun.edu 


\title{
AN OVERVIEW OF FAMILY SYSTEMS APPROACHES TO LIBRARY MANAGEMENT
}

By Mark Stover

\begin{abstract}
$\underline{\text { ABSTRACT }}$
Family systems theory has often been applied to the organizational environment. This article presents an overview of family systems approaches to management, with particular focus on libraries and information technology. Some of the family systems concepts that can be applied to the library environment include differentiation, mystification, emotional triangles, and pseudomutuality. Some of the positive aspects of a family system that are relevant to the organizational context include stages of development, family rituals, and family stories. Through examples and vignettes, the author demonstrates the application of family systems theory to the field of library management.
\end{abstract}

\section{$\underline{\text { KEYWORDS }}$}

Organizational Behavior; Family Systems Theory; Libraries; Management; Information Technology 


\section{$\underline{\text { INTRODUCTION }}$}

Experts in organizational behavior have long known that emotional issues are an important part of the interpersonal dynamics that take place within organizations (Fineman, 1993; Ashkanasy et al., 2002; Lord et al., 2002; Comella et al., 1996). These issues have been acknowledged within the library literature as well as in other spheres (Bull, 2002; Gass and Sheffield, 1995).

However, most of the literature dealing with the emotional aspects of organizational life has focused on individual and "intrapsychic" facets of the organization instead of on the systemic nature of groups and organizational behavior. In regard to this common understanding of organizations, Hall (1981, p. 170) writes: “If groups malfunction, the problem is usually believed to be the result of a specific organizational or social influence rather than the expected response of a group to emotional tension or trauma.” By contrast, the work of family systems theorists such as Bowen (1978) provides a framework for which group behavior can be viewed as systemic, contextual, and interconnected. Failure to recognize the systemic nature of an organization may result in increased absenteeism, low morale, loss of key employees, corporate anxiety, interpersonal conflict, and breakdowns in communication (Hall, 1981, p. 170).

Family systems theorists have identified several dysfunctional types of relationships that need to be avoided. These unhealthy forms of relating are important to recognize in small families or large corporations, in face to face conversations or in networked electronic discussion groups (Hall, 1981, pp. 169-180; Sagar and Wiseman, 1982; Comella et al., 1996). As Murray Bowen, a pioneer in the field of family systems theory, writes: "Basic relationship patterns developed for adapting to the parental family 
in childhood are used in all other relationships throughout life. The basic patterns in social and work relationships are identical to relationship patterns in the family" (Bowen, 1978, p. 472).

Along with negative relational patterns, family theorists have also discovered positive themes that appear in both families and organizations. These include family stories and myths, family stages of development, and family rules and rituals. Just as the negative relationships within families can be seen in organizations, so these positive family patterns can be applied to the organizational setting.

This article will present an overview of family systems approaches to management, with particular focus on libraries and information technology. Through examples and vignettes, the author will demonstrate the application of family systems theory to the field of library management. This approach is important for library managers to understand and incorporate for several reasons. First, family systems theory recognizes the systemic and interconnected nature of organizations. This places individuals and departments in the context of the entire system, and avoids scapegoating and other forms of blame-shifting. Second, family systems theory is honest and authentic in the way it views organizational patterns and structures. It does not allow "pseudomutual” forms of relationships, and it encourages candid and open communication. Third, family systems theory recognizes that while organizational systems naturally gravitate toward the setting up of human connections, there are healthy and unhealthy ways of "connecting” within such a system. Family systems theory discourages emotional triangles and collusion, and it encourages healthy differentiation from other employees and from the organization itself. Fourth, family systems theory 
respects the dignity of the individual. It promotes healthy boundaries between and among employees, and it seeks to avoid mystification and double-binds that can occur when management is not aware of the family dynamics of organizational behavior.

\section{DIFFERENTIATION AND FUSION}

A certain level of autonomy is important for any individual, whether in a family or in an organization. Autonomy represents the degree of independence that an individual needs to function apart from others in the system. Fusion (sometimes called “enmeshment”) is the absence of differentiation, when an individual becomes attached to another person to the extent that blurred emotional boundaries and interdependency are the end result. A high degree of differentiation is generally healthy, while a high degree of fusion is often pathological (Simon et al., 1985, p.366).

While the concepts of differentiation and fusion evolved from the study of family relationships, Bowen (1978, pp. 461-465) has demonstrated that a recognition of healthy and unhealthy forms of differentiation are just as valid in the workplace environment. Healthy workplace differentiation allows positive relationships to flourish without an erosion of boundaries and overly dependent reliance on one or more individuals. Overly “fused” or "enmeshed” organizations (or groups within organizations) tend to be emotionally intense, anxious, and resistant to change (Hall, 1981, pp. 171-172).

Managers in the library need to strive for differentiation and avoid fused relationships. An example of fusion in the information technology context might occur when one staff member becomes overly reliant on another staff person for computer assistance or training. One employee (George) feels uncomfortable with technology and 
becomes attached to his own personal computer "guru" (Deborah). Every time George needs to learn anything new (for example, a new software application), he calls upon Deborah to walk him through the process. Eventually, the slightest change in George's computer comfort level causes him to head straight for Deborah's cubicle, where he will find solace and nurturing for his technological ills. George needs to somehow "differentiate" from his computer mother Deborah. Otherwise, the fused and dependent relationship will ultimately stifle George's learning abilities, prevent Deborah from spending enough time on other projects and staff members, and generate resentment among other employees.

\section{TRIANGLES}

Emotional triangles occur when a third person is brought into a stressful dyadic relationship to create balance and relieve tension (Bowen, 1978, pp. 478-480). For example, a dispute may take place between two employees, and a third employee might involuntarily be brought into the debate. We would say that this third employee was “triangled,” which may produce some temporary relief for one employee but will ultimately end up creating a whole new set of problems for everyone involved. After an emotional triangle has been created, de-triangling (becoming emotionally detached or neutral), though difficult to achieve, should be attempted (Kerr and Bowen, 1988, pp. 150-162). While triangles are not optimal, they are often a necessary component of organizational life because they tend to alleviate symptoms caused by organizational anxiety and lack of managerial differentiation (Hall, 1981, p. 176). 
Emotional triangles are quite common in libraries. Arguments over technology are often extended to outside parties in an effort to win the dispute or relieve anxiety. Email technology is especially useful in triangling, with "carbon copy" and "blind carbon copy" functions only a keystroke away. A more extreme version of triangling occurs when one participant in an argument sends copies of his or her correspondence to an entire online discussion group. Library managers should resist the impulse to triangle others using email or other communication methods, since it ultimately damages relationships and creates misunderstandings.

\section{$\underline{\text { MYSTIFICATION }}$}

Whenever people live, work, and communicate with each other, mystification occurs. Mystification refers to the process that is created when one or more members of a system fails to understand the meaning and/or purpose of a communique from another member. This often places the mystified person(s) in a "one-down" position, which disempowers them and fails to produce a clear message. Corsini and Wedding (1989, p. 596) call this “a pattern of confusion, chaotic, and unclear communication, or doubletalk.” This type of obfuscation is sometimes used as a subtle and unconscious form of manipulation that seeks to influence others or change their behavior (Foley, 1989, p. 462).

The goal of any good communicator is demystification. In the library, mystification occurs for a variety of reasons. Staff members are mystified when they receive emails that contain unfamiliar jargon of any kind. They are mystified when they are expected to utilize a particular software application and are clueless about its 
functionality. They are mystified when changes appear in their computer systems (operating system, desktop, applications, hardware, etc.) without any advance notice. A good library manager will prevent his or her employees from becoming mystified especially regarding technology and email communications.

\section{BOUNDARIES}

All individuals need boundaries. The absence of boundaries produces unclear limits in terms of what others may or may not say or do to a person. However, sometimes boundaries can be overly rigid, which creates individuals who are unable to emotionally relate to others. Ideally, individuals, families, and organizations can maintain flexible boundaries which set reasonable limits on others yet at the same time allow accessibility (Simon et al., 1985, pp. 25-28).

Managers must keep a balance between complete detachment from their employees and enmeshment in the emotional lives of their staff. Proper boundaries assist in this effort. While some have traditionally viewed managers as being responsible for the behavior of their subordinates, systems theory would advocate a stance that would allow each individual in the organization to have "ownership" over their own behavior (Hall, 1981, pp. 173-174). Managers "will be more effective if they relinquish their emotional control over others” (Hall, 1981, p. 174). Moderation in setting boundaries helps managers avoid "overresponsibility” and encourages autonomous, responsible behavior in all employees.

Libraries, and the people who staff them, need flexible boundaries. A good metaphor for emotional boundaries is the infamous computer "firewall." Good firewalls 
maintain a balance between allowing entry to welcomed guests and prohibiting entry to unwelcomed intruders. In the same way, flexible boundaries allow relational access but prevent relational abuse. An individual with flexible boundaries will generally prohibit use of his or her computer by others, unless good cause can be shown (or unless a mutually beneficial arrangement can be agreed upon in advance). A department with flexible boundaries will share computing and information resources with other departments yet at the same time not allow its own system resources to be misused or abused.

\section{OPEN AND CLOSED SYSTEMS}

General systems theory espouses the idea that all systems, including families and organizations, are to some degree either open or closed. An open system allows in new information and is willing to change. A closed system is isolated, limits information flow, and resists change (Van Gigch, 1978, p. 41). Clearly, open systems are preferable to closed ones, since open systems welcome new data, look at situations from different perspectives, and are willing to change if necessary (Mettal, 1977; Foley, 1989, p. 456).

A good example of a closed technological system is an organization or department that refuses to allow its members to connect to the outside world through the Internet. Some managers rationalize this stance by focusing on the potential abuses that can occur when a local network is wired to a global network, such as misuse of email or downloading pornography. In reality, open systems, like an Internet connection available to all employees, generate creativity and synergy, while closed systems breed mistrust, resentment, and stagnant workflow. Open systems are risky in that they allow potentially 
abusive situations to occur, but most library managers will find that these risks are more than outweighed by the positive side effects engendered by an open and trusting work environment.

\section{COLLUSION}

The word collusion carries with it all sorts of conspiratorial baggage, but as family psychologists use it the term is much less ominous. Members of a family or organization "collude" (often unconsciously) with each other to maintain certain "secrets" and to stabilize relationships (Simon et al., 1985, pp. 50-52). While collusion maintains the status quo of a family or an organization, it also prevents individuals from talking about secretive issues that probably should be uncovered and discussed (Williams, et al., 1980).

How is collusion reflected in the library context? It can take on a number of different incarnations, but usually it appears when one employee covers up the deficiencies of another employee. Jane is "colluding" with Richard when she covers up his lack of computer knowledge by performing certain tasks for him (e.g., online searches, Web authoring, etc.). By refusing to continue the collusion process she would expose his lack of expertise to others, which at first might appear harsh and cruel but ultimately would be healthy and beneficial for both Jane and Richard.

\section{DOUBLE-BIND}


Emotional double-binds occur when one person (usually a supervisor or someone in a similar kind of "one-up" or parental position) gives two mutually exclusive messages which require contradictory action on the part of a second person or group (Simon et al., 1985, pp. 96-99). This has been referred to in the literature as "paradoxical communication” (Watzlawick et al., 1967) or a "no win” situation (Sluzki and Ransom, 1976). The relationship between the two parties is often such that no discussion (or "metacommunication") about the double messages is permissible, and the result is usually mystification and paralysis. Double-binds are hurtful and unfair, and they should be broken and exposed whenever possible.

For example, Susan's supervisor has asked her to install Web authoring software on all the computers in her department. However, Susan is aware that the department has only purchased a single user license for this application. In addition to the copyright laws that would be violated, Susan has also read the employee manual which specifically prohibits this kind of activity. Susan's supervisor has placed her in a double-bind. If she follows her conscience and refuses to break the law, she risks incurring the wrath of her supervisor and the accusation of insubordination. If she obeys her supervisor's directive, she will break the law and violate company policy. On the surface, at least, Susan is in a "lose-lose" situation.

A somewhat different kind of double-bind occurs when a supervisor instructs her subordinates to behave in a certain way, but then sends a different message through nonverbal communication. For example, Rosemary has told her employees to come to her with any problems that they encounter, yet when this happens her body language (crossed arms, upset facial expressions) and other nonverbal cues (slamming doors) 
communicate the opposite and thus place the subordinates in an emotional and organizational dilemma.

Library managers need to be extremely careful not to place their subordinates in these kinds of double-bind dilemmas. Soldow (1981) recommends a variety of ways that the organizational double-bind can be avoided, including using precise language, clarifying organizational policies, and converting nonverbal communication into verbal communication as often as possible.

\section{$\underline{\text { SCAPEGOATING }}$}

Most families have one member that seems to cause all the problems. This member carries the tag of "troublemaker," “crazy,” or any number of other pejorative labels, and usually becomes the scapegoat of the entire system's problems (Simon et al., 1985, pp. 308-309). Many theorists believe that this person, rather than being the true source of pathology, is merely "the object of displaced conflict or criticism" (Nichols and Schwartz, 1991, p. 593). In clinical settings, this person is called the "identified patient."

Organizations often have an "identified problem person" as well. Kern and Peluso write:

In organizational terms, the dynamics of the problem employee may be described as a difficult personality type, an unmotivated worker, or one lacking certain work-related skills. The difficult employee may suffer from confusion in role function, lack of adequate supervision, poor hiring 
practices, underuse of employee resources, or the inability to cope with or understand the correct way of fitting into the organizational culture. From a family systems perspective, the individual described as the identified patient is one who acts as the symptom carrier of much more deeply embedded dysfunction within the family or organization. The identified patient could be a result of unhealthy coalitions, triangulation, or boundary issues. However, the identified patient, according to many family systems theorists, is considered to be the healthiest member of the system for calling attention to the broader, system-wide problems by his or her actions (1999, p. 242).

The problem employee, who is almost always a subordinate or junior member of the organization, is (according to family systems theory) simply displaying the "symptoms" of an unhealthy organization. In systems theory, just as the behavior of one individual can affect the entire system, so the attitudes and dysfunctionality of the system as a whole can generate erratic behavior on the part of one individual. The "identified patient" is often the opposite of the elephant in the room, since no one dares to talk about the elephant but everyone loves to blame a scapegoat. While some superficial attempts to solve the problem (such as termination of an employee, or restructuring the organization) may have short-term success, in the long run someone else in the library will most probably begin to act out (often in new ways) the sickness of the system.

\section{$\underline{\text { CUTOFFS }}$}


Emotional cutoffs occur in families or organizations when one person becomes angry with or alienated from another person (Simon et al., 1985, p. 106). Sometimes the cutoffs extend to entire departments. The end result could be a complete breakdown in communication, where one individual (or department) simply refuses to speak with another individual (or an entire department). Usually, however, cutoffs are more subtle, where one member, whether consciously or unconsciously, decides to limit communication, accessibility, and interaction to a basic minimum. Bowen (1978, p. 535) calls this "emotional distancing." Cutoffs are fairly common in families and in organizations, but they can cause tremendous damage throughout the system.

The following anecdote exemplifies the concept of cutoffs in an organization. Roger was the head of information systems at a medium sized biotechnology company. He had been feuding with Peter, the director of the library, for several years over a misunderstanding that had occurred between the two men. Roger had felt hurt and used by Peter, and this resulted in Roger effectively cutting off Peter, refusing to speak with him when they met in the hallway and barely acknowledging his presence whenever their paths crossed in meetings. Emails from Peter often went unanswered by Roger for weeks at a time. But it wasn't just the personal relationship between Roger and Peter that suffered. Requests for technical support from any library staff member were sometimes ignored by Roger and his staff. Upgrades to library hardware and software often took months before they were completed. Confrontations between Peter and Roger only resulted in excuses being made and further distance between the two men. Peter pleaded for help from management, but this did not help matters since all other departments except for the library received quality service. The story of Roger and Peter demonstrates 
the huge problems that can occur when personal issues cause cutoffs at the departmental level.

\section{PSEUDOMUTUALITY}

Pseudomutuality refers to relationships that appear to be civil and even externally congenial, but in reality (underneath the surface) are bitter, resentful, and in disarray. This has been termed "the façade of harmony" (Simon et al., 1985, p. 272). Early family therapists believed that pseudomutual families were "the result of a systemic family effort to blur distinctions and boundaries, which is felt to be necessary because these allow clear disagreement and disagreement is felt to be catastrophic" (Gustafson, 1976, p. 990). The members of a pseudomutual group resist change and differentiation, and the use of language is vague and imprecise (so that group consensus can more easily be reached). A pseudomutual group is "fused" (in the negative sense) and does not allow individual expression or autonomy. Later theorists applied the pseudomutual label to organizations as well as to families (Gustafson, 1976).

The following story illustrates the notion of pseudomutuality in organizations. Derek, the director of a small academic library, was an eternal optimist. He enjoyed bantering with his staff and a smile never seemed to leave his face. But his smiling demeanor belied a dark side of library operations. All of the staff knew that the worst sin that could be committed in Derek's presence was any sort of criticism, negativity, or pessimism. A “positive attitude” was Derek’s motto, but his lack of toleration for anything else led staff to hide their feelings, keep silent during meetings, and avoid 
confrontation. Most relationships at the library were superficial at best, due to the stigma against authentic expression of thoughts and feelings. Resolution of real conflicts took second place to "putting on a happy face.”

While some may believe that a pseudomutual state of affairs is harmless and perhaps even good for morale, the opposite is in fact true. In libraries as in all other organizations, pseudomutuality can affect not just individual relationships but entire departments, and it can easily hinder open and honest communication. Some libraries may emphasize "getting along with one another", but this principle should not stand in the way of freedom to disagree and voice dissent.

\section{ELEPHANT IN THE ROOM}

Derived from the literature of alcoholism and addiction, the "elephant in the room” is the problem that no one wants (or dares) to talk about. Like their namesakes, emotional elephants are often large and threatening, and are clearly visible to those who would only open their eyes. Fear and shame are two common factors that prevent us from discussing the elephant problem. Individuals are often afraid of retaliation if they speak about the real issues, but they are just as often ashamed of the problem and sometimes blame themselves. Those who refuse to acknowledge the elephant in the room are said to be in denial. Those who assist the elephant in maintaining his invisible presence are called enablers. A prevalent example of this phenomenon is the existence of alcoholism in a family, but the elephant can take many other manifestations as well, in both small and large organizations. 
Libraries have their share of elephants. In fact, one could argue that electronic communication often brings elephants out of the closet when previously they could stay hidden. One common elephant in today's library is the presence of managerial perks that undermine professional and clerical staff. When managers demand leading edge technology while others in the library are forced to make do with older equipment, morale and productivity both suffer. Another elephant in the library is the occurrence of unprofessional behavior stemming from personal relationships in the organization. One department may go untrained and unsupported in the arena of technology because of feuds or personality conflicts, while another department, whose members enjoy a personal friendship with the computer guru, will find compliance and support at every step.

Why would we describe these scenarios as "elephants in the room"? First, because many in the organization are unwilling or unable to acknowledge the existence of these dysfunctional situations. Second, because the person who dares to point out these problems will likely face retaliation, either through active measures like termination or through passive action (such as an even slower response to computer support requests). The library manager must be aware of the various kinds of elephants that may invade our workspace, and must be prepared (even in the face of potential conflict) to take action against them.

\section{FAMILY STORIES AND MYTHS}


All of us tell stories in every aspect of life, including work. Storytelling helps us bring to life (through narrative and metaphor) our hopes and dreams as well as our fears and disappointments (Gargiulo, 2002). When we tell a story about ourselves or someone we know, we are simply relating our point of view of an event that occurred. This explains why different people can experience the same event and yet give completely different accounts. Stories reveal our biases and perceptions, but they also help us to voice the concerns of life. In addition, stories can assist us in working through past problems and future difficulties that we must overcome. Stories are generally healthy forms of coping, but they must be viewed as life seen through the lens of one individual.

Family myths are a form of storytelling that explain and defend the family's position in society or in relation to other families or individuals (Simon et al., 1985, p. 132-134). Often, family myths articulate and justify unhealthy patterns in families and organizations. Nichols and Schwartz (1991, p. 590) call these "a set of beliefs based on a distortion of historical reality and shared by all family members that help shape the rules governing family functioning.” For example, families may have mythical explanations to rationalize poverty, wealth, or migration. Like families, most organizations have a mythological subculture that explains the choices of individuals and groups within the organization.

Libraries have no shortage of stories and myths. Everyone remembers (and has their own version of) the time that the network was down for 3 days, or the time that the server's hard drive crashed and the library’s backup tapes were found to be corrupted. People will tell stories that explain why they are always the last to be upgraded in their department, or why Joe over in the Reference department always has a brand new 
computer on his desk. Stories can deceive and mislead, but in the library world they more often allow employees to vent their frustrations over technology gone awry, process their problems, and voice their fears. Library managers need to allow technology stories to be told (and to create their own narratives as well), if only to relieve stress and promote imagination and creativity. On the other hand, managers should be aware of any "mythology" that appears to distort reality and perpetuate dysfunctional attitudes and practices.

\section{STAGES OF DEVELOPMENT}

Each of us goes through various stages of development in our physical and emotional growth. As we mature, we move from one stage to the next of emotional and physical development. For example, developmental psychologist Erik Erikson (1964) discovered various stages through which children grow and develop, including trust, autonomy, identity, and intimacy. Others have researched the ways that both children and adults develop in different ways, including moral, cognitive, spiritual, intellectual, emotional, and behavioral development (Kohlberg, 1984; Fowler, 1981). Families, like individuals, also experience stages of development as they age and mature (Carter and McGoldrick, 1999; Schultz, 1984, pp. 155-191). While organizations are not the same as families, they too may mimic the life cycle and developmental stages of individuals and family units. For example, an organization such as a library (or the staff of that library) might be more playful and flexible in its early years, much like a child. As it enters its "adolescence," the organization might begin to take new risks and cross new boundaries. During its "middle age" or adult years, the organization might become more rigid and 
settled in its policies and standards, and as it reaches "old age" it might gain accumulated "wisdom" that often comes with maturation.

I would propose that libraries, and the people who work within these libraries, often experience similar kinds of growth in relation to technological change. Some libraries, perhaps at an "adolescent" stage of development, may take risks with technology. Others, at a younger stage, might retain a good deal of flexibility in the ways that they relate to technological change. Still other libraries, at the more mature adult stage, might have firm and rigid policies about computer use. One must remember that these stages of growth are not pejorative in any way. One stage is simply different than another, without any implication of superiority. Of course, there are advantages and disadvantages to each state of development (such as risk taking), but to label a library as being at a particular stage of development is simply a descriptive exercise and not in any way judgmental.

\section{RULES AND RITUALS}

Every family and organization has its own set of "rules" and "rituals" that are at the same time self-defining and self-regulating (Simon et al., 1985, p. 306-308; Kern and Peluso, 1999, p.239; Imber-Black et al, 1988). The rules are almost always unwritten and rarely acknowledged, but they are powerful regulators nonetheless. An example of an organizational rule might be that the library director is never challenged, or that jokes are not permissible during certain kinds of meetings. Another example might be that all members of the organization must always appear to "get along with each other" (pseudomutuality). While these rules will never find their way into the library's employee 
handbook, they are nevertheless known and obeyed by most staff. Unwritten rules have their place, but they can become counter-productive when employees are unable or unwilling to talk about them.

Rituals are similar to rules in that they are unwritten and commonly accepted (Rothenbuhler, 1998). Each organization takes part in these rituals on a regular basis, which can be anything from monthly (or weekly) staff meetings to company picnics to going-away parties. Rituals are an important part of organizational life and can benefit staff morale. They should not be eliminated without careful consideration.

\section{CONCLUSION}

There will be some barriers when library managers attempt to implement a family systems strategy. Not all employees will be comfortable with this perspective. Some employees may resist differentiating and may attempt to continue to use triangles as a communication method. Finding a balance between rigid boundaries and no boundaries at all may prove difficult for some staff. While it is never easy to be a scapegoat or to be the recipient of a cutoff or a double-bind, some employees may identify as victims and thus may not wish to take on the responsibilities that would be entailed by the removal of family systems pathology in the corporate culture. Perhaps the biggest barrier to a successful implementation of family systems theory in the library context is the excision of pseudomutuality. Employees who are accustomed to a pseudomutual environment may find it difficult to trust the new manager who does not insist on a harmonious façade. It is one thing for a manager to tell her staff that she is open to hearing about all sorts of 
problems; it is another thing for the staff to actually witness the reality of this manager tolerating criticism and confrontation without her "killing the messenger."

Future researchers might explore the application of family systems theory to libraries in various ways. Qualitative or quantitative studies might be undertaken to measure the effects of family systems theory as applied to library management. Assessment tools could be created that would determine the usefulness of this theory in the library workplace. There are currently a number of instruments related to family systems theory that are available for researchers (Perlmutter et al., 2001; Gehring and Page, 2000). These tests could easily be adapted for use in the library and information services environment.

The recognition that all organizations, including libraries, are "emotional systems" is crucial to managerial success. Library managers must learn to avoid negative emotional reactivity that is displayed in various ways, including mystification, emotional triangles, scapegoating, and pseudomutuality. They must also accept the reality of (and the positive aspects of) the emotional patterns that tend to appear in all organizations, including organizational stages of development, rules and rituals, and storytelling. In this way, library managers can provide a responsible model for all employees at every level of the organization through reduced anxiety, clear communication, and openness to change. 


\section{REFERENCES}

Ashkanasy, N.M., Zerbe, W.J. and Hartel, C.E.J. (2002), Managing Emotions in the Workplace, M.E. Sharpe, Armonk, NY .

Bowen, M. (1978), Family Therapy in Clinical Practice, Jason Aronson, New York.

Bull, J. (2002), “Managing the emotional side of change.” Library Mosaics 13, 11-12.

Carter, B. and McGoldrick, M. (1999), The Expanded Family Life Cycle: Individual, Family, and Social Perspectives, Allyn and Bacon, Boston.

Comella, P.A., Bader, J., Ball, J.S., Wiseman, K.K. and Sagar, R.R. (1996), The Emotional Side of Organizations: Applications of Bowen Theory, Georgetown Family Center, Washington, DC.

Corsini, R.J. and Wedding, D. (1989), Current Psychotherapies, F.E. Peacock, Itasca, IL.

Erikson, E. (1964), Childhood and Society, Norton, New York.

Fineman, S. (1993), Emotion in Organizations, Sage, New York.

Foley, V.D. (1989), “Family therapy,” in Corsini, R.J. and Wedding, D. (Ed.), Current Psychotherapies, F.E. Peacock, Itasca, IL, pp. 455-500.

Fowler, J.W. (1981), Stages of Faith: The Psychology of Human Development and the Quest for Meaning, Harper and Row, San Francisco.

Gargiulo, T.L. (2002), Making Stories: A Practical Guide for Organizational Leaders and Human Resource Specialists, Quorum Books, Westport, CT. 
Gehring, T.M. and Page, J. (2000), “Family System Test (FAST): A Systemic Approach for Family Evaluation in Clinical Practice and Research,” in Gitlin-Weiner, K., Sandgrund, A., and Schaefer, C. (Ed.), Play Diagnosis and Assessment, John Wiley and Sons, New York, pp. 419-436.

Gass, E. and Sheffield, J. (1995), “Library management of interpersonal relationships between employees.” Indiana Libraries 14, 43-50.

Gustafson, J.P. (1976), “The pseudomutual small group or institution.” Human Relations 29, 989-997.

Hall, C.M. (1981), The Bowen Family Theory and its Uses, Jason Aronson, New York.

Imber-Black, E., Roberts, J. and Whiting, R.A. (1988), Rituals in Families and Family Therapy, Norton, New York.

Kern, R.M. and Peluso, P.R. (1999), “Using individual psychology concepts to compare family systems processes and organizational behavior.” Family Journal 7, 236244.

Kerr, M.E. and Bowen, M. (1988), Family Evaluation: An Approach Based on Bowen Theory, Norton, New York.

Kohlberg, L. (1984), The Psychology of Moral Development: The Nature and Validity of Moral Stages, Harper and Row, San Francisco.

Lord, R.G., Klimoski, R.J. and Kanfer, R. (2002), Emotions in the Workplace: Understanding the Structure and Role of Emotions in Organizational Behavior, JosseyBass, San Francisco. 
Mettal, W.G. (1977), “Cybernetics, general systems, and creative problemsolving.” Journal of Creative Behavior 11, 53-66.

Nichols, M.P. and Schwartz, R.C. (1991), Family Therapy: Concepts and Methods, Allyn and Bacon, Boston.

Perlmutter, B.F., Touliatos, J. and Holden, G.W. (2001). Handbook of Family Measurement Techniques, Sage, Thousand Oaks, CA.

Rothenbuhler, E.W. (1998), Ritual communication: from everyday conversation to mediated ceremony, Sage, Thousand Oaks, CA.

Sagar, R.R. and Wiseman, K.K. (1982), Understanding Organizations: Applications of Bowen Family Systems Theory, Georgetown University Family Center, Washington, DC.

Schultz, S.J. (1984), Family Systems Therapy: An Integration, Jason Aronson, New York.

Simon, F.B., Stierlin, H. and Wynne, L.C. (1985), The Language of Family Therapy: A Systemic Vocabulary and Sourcebook, Family Process Press, New York.

Sluzki, C.E. and Ransom, D.C. (1976), Double bind: the foundation of the communicational approach to the family, Grune and Stratton, New York.

Soldow, G.F. (1981), “Change in the organization: the detriment and benefit of the double bind.” Group and Organization Studies 6, 500-513.

Van Gigch, J.P. (1978), Applied General Systems Theory, Harper and Row, New York. 
Watzlawick, P., Beavin, J.H. and Jackson, D.D. (1967), Pragmatics of Human Communication: A Study of Interactional Patterns, Pathologies, and Paradoxes, Norton, New York.

Williams, N., Sjoberg, G. and Sjoberg, A.F. (1980), “The bureaucratic personality: an alternate view.” Journal of Applied Behavioral Science 16, 389-405. 